\title{
Assessing Process Skills in Engineering Students
}

\author{
Darlene Spracklin-Reid, Susan Caines, and Andrew Fisher \\ Memorial University \\ darlenesr@mun.ca sjc184@mun.ca adfisher@mun.ca
}

\begin{abstract}
Assessing process skills in an undergraduate engineering program is an important and complex issue. Attributes like teamwork, ethics and professionalism are subjective skills that are difficult to accurately assess. At Memorial University's Faculty of Engineering and Applied Science (FEAS), these skills are developed and assessed in ENGI 7102, The Engineering Profession. The course uses one-on-one interviews, small group discussions, a close connection to capstone design work and a blended approach to theory that allows for face-toface activities and assessment. This paper will describe the methodology for the course development and instructional design, along with a discussion of the activities and assessments that capture process skill attributes for evaluation. In addition, ENGI 7102 's role in assessing graduate attributes for accreditation will be highlighted.
\end{abstract}

Keywords: Professional skills, graduate attributes, accreditation, assessment.

\section{INTRODUCTION}

Process or professional skills are essential for professional engineering practice. While engineers are expected to have strong technical skills, problem solving, analytical and design skills can be difficult to implement without the accompanying professional skills [9]. In addition, studies show that engineers actually spend a majority of their working time engaged in activities that primarily use their professional skills [11]. Professional skills are needed and essential, but teaching and assessing these skills is challenging. While there is an acknowledged need for engineering students to acquire professional skills, they can be difficult to teach and assess [1]. Comprehensive lists exist of professional skills; however there is limited knowledge about how these skills are embodied and how formative and summative assessment can be best used to help students develop these skills [5].

The Canadian Engineering Accreditation Board $(\mathrm{CEAB})$ requires that a number of these professional skills be demonstrated by graduating engineers [3]. See Figure 1. ENGI 7102 The Engineering Profession is taught in the final semester of the engineering program and is required for all students. In this course, professional skills are taught and assessed using a blended approach and a close connection to the capstone design project in each discipline. This course was redeveloped in an attempt to better teach and assess professional skills and to link these assessments with graduate attributes as a measure for accreditation purposes. In addition, the course is part of the continuous improvement and feedback loop that is an essential component of Memorial University's accreditation workflow. This redevelopment focused on being intentional about the development of

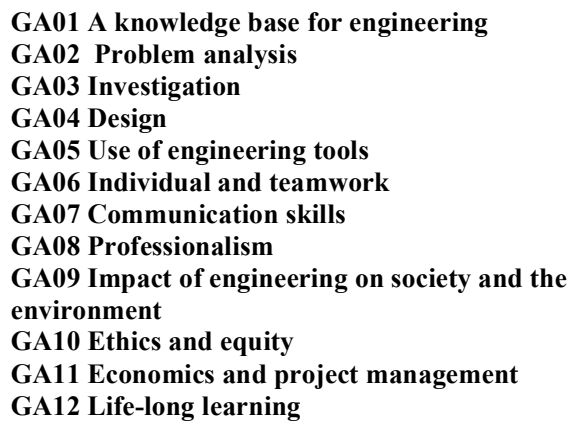

Fig. 1. CEAB Graduate Attributes 1

professional skills, providing formative feedback in an effective way and creating a bridge between professional and technical skills.

\section{ENGI 7102}

\subsection{Motivation for Redevelopment}

ENGI 7102 The Engineering Profession examines the origins and development of Engineering as a profession and its values, the place of technology in society and the nature of technological decisions. Topics include the role and responsibility of the professional engineer in society, code of ethics, sustainable development and environmental stewardship [8]. In response to the CEAB's outcomes accreditation requirements, ENGI 7102 was redeveloped to ensure that the graduate attributes most closely associated with professional skills were being taught and assessed. The graduate attributes that are focused on in this course are: 
- Individual and teamwork: An ability to work effectively as a member and leader in teams, preferably in a multi-disciplinary setting.

- Communication skills: An ability to communicate complex engineering concepts within the profession and with society at large. Such ability includes reading, writing, speaking and listening, and the ability to comprehend and write effective reports and design documentation, and to give and effectively respond to clear instructions.

- Professionalism: An understanding of the roles and responsibilities of the professional engineer in society, especially the primary role of protection of the public and the public interest.

- Impact of engineering on society and the environment: An ability to analyze social and environmental aspects of engineering activities. Such ability includes an understanding of the interactions that engineering has with the economic, social, health, safety, legal, and cultural aspects of society, the uncertainties in the prediction of such interactions; and the concepts of sustainable design and development and environmental stewardship.

- Ethics and equity: An ability to apply professional ethics, accountability, and equity.

- Life-long learning: An ability to identify and to address their own educational needs in a changing world in ways sufficient to maintain their competence and to allow them to contribute to the advancement of knowledge. [3]

\subsection{The Role of ENGI 7102 in Accreditation}

ENGI 7102 forms part of a stream of learning that begins in ENGI 3101 The Engineering Workplace and continues over four work terms (Figure 2). The learning stream includes traditional face-to-face classes, online learning and work term experiences. To develop lifelong learning skills, it is recommended that hands-on experiences be included, along with appropriate flexibility in time and space to give students ownership and control of their learning within the constraints of the curriculum [12].

In ENGI 3101, students are introduced to the skills that are required for successful integration into a work term placement. It is a course that deals with issues associated with professional engineering practice including workplace and professional ethics, public and workplace occupational health and safety, equity, gender, diversity, and technical communication [8]. ENGI 3101 begins the process of preparing students for professional practice and gives students the tools and techniques they need to be reflective learners.

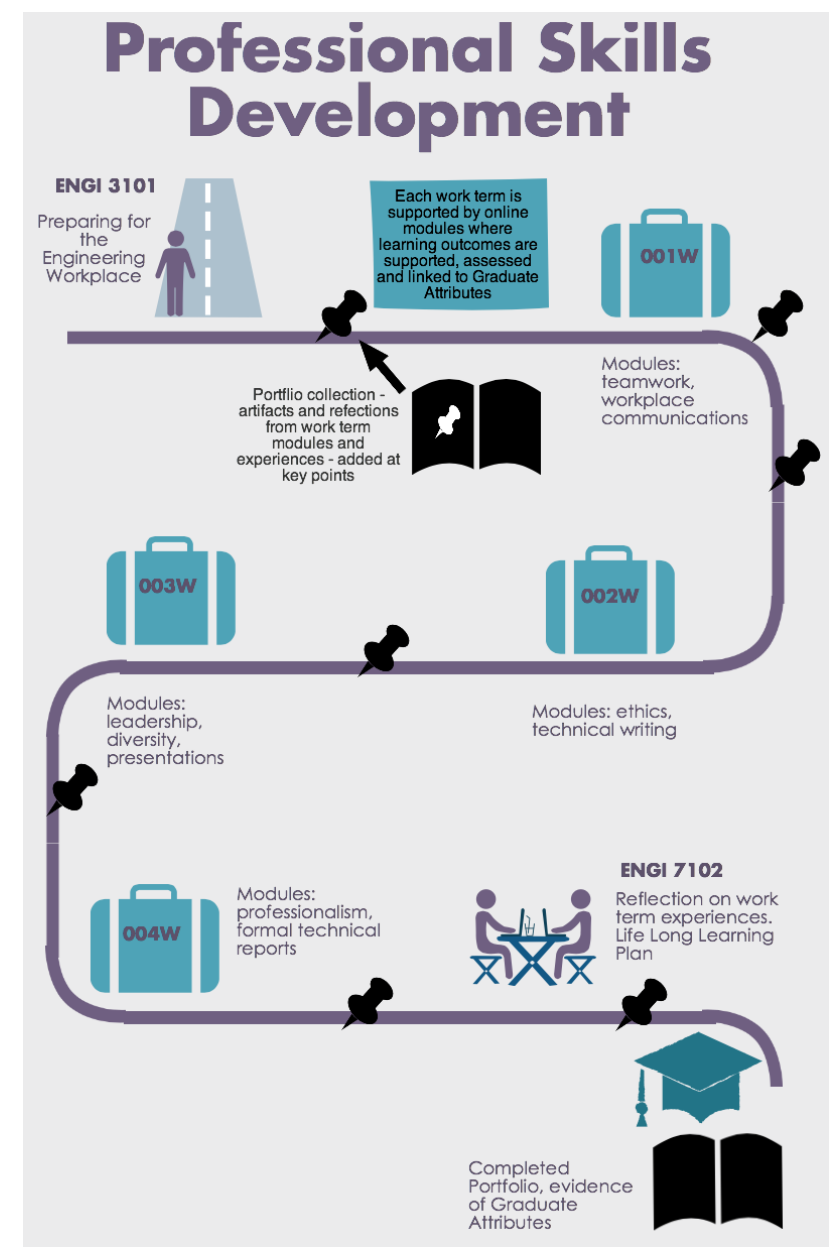

Fig. 2. Professional Skills Development Stream

Following ENGI 3101, students are required to complete four work terms. Each of these work terms will require students to complete learning modules that support the development of professional skills, including leadership, teamwork and communication. Students will study these topics online and draw on their work term experiences for reflective assessments.

This blended approach allows students to connect theory and practice. For example, in the leadership module, students will learn about theories of leadership and then use these theories to identify types of leadership in the organization where they are working and connect the theory and practice to examine their own leadership abilities and leadership style. Interaction between professional and technical skills is critical. An integrated approach where students can directly connect their professional and technical work, the engineering objectives they pursue and their future careers should be implemented wherever possible [5]. 
ENGI 7102 is the final stage of the professional skills development process. Students are required to demonstrate their professional skills by drawing on experiences from their work terms and applying them in the context of their senior design project. They examine their own skill sets and create a lifelong learning plan to help them continue to grow as professionals.

As the learning outcomes are assessed in ENGI 7102, the graduate attributes they are linked with are measured. Targets and thresholds are set and a report on the levels achieved by students is generated for review by each Department Committee. This report, along with the survey results and exits interviews that are also a part of ENGI 7102, is a critical piece of the feedback loop that is part of the accreditation workflow, (Figure 3).

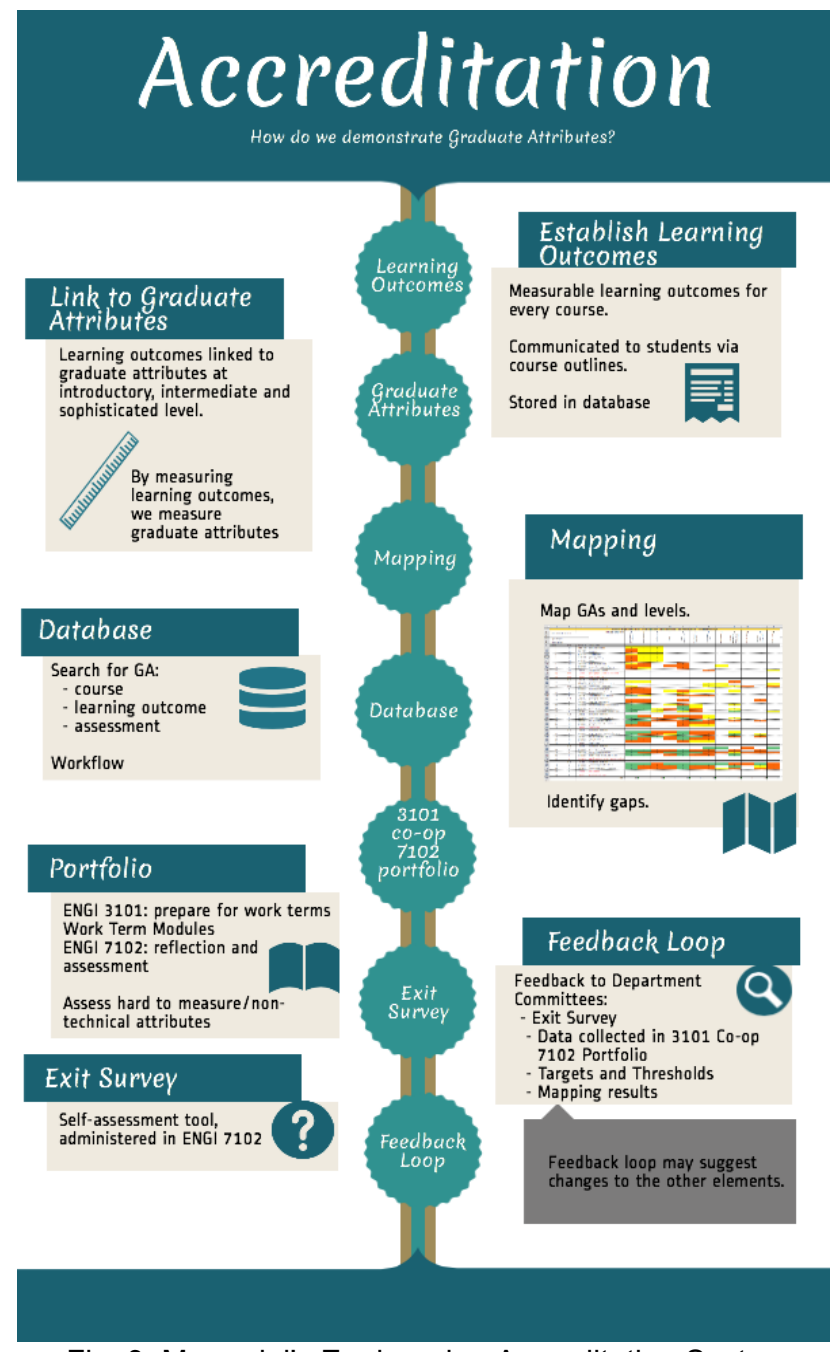

Fig. 3. Memorial's Engineering Accreditation System

At the end of the professional skills development process, students will have a portfolio of their work, their reflections and a plan for lifelong learning. Establishing and embedding graduate attributes is not sufficient to ensure that graduates can express what they know or make connections to lifelong learning. Portfolios can be used to capture evidence of learner development and help make these kinds of connections. Feedback is included throughout the process as formative feedback from staff, peers and professional mentors can encourage and support the development process and facilitate transforming learners into professionals [4].

\subsection{Course Structure}

ENGI 7102 is offered using a blended approach. Students attend a face-to-face classroom session for an hour once a week and complete readings, activities and assignments online. The course also included small group meetings and individual student interviews.

This blended method of delivery was chosen to allow students the opportunity to come together to engage in discussions and activities on a regular basis, while allowing them to have flexibility in the completion of assignments. Content was largely delivered online and assignments were submitted using the dropbox feature of the Desire2Learn course shell. Class time was used for interactive activities and group discussions. This type of blended delivery was also chosen so that small group meetings and individual interviews could be scheduled throughout the term.

Students come in to ENGI 7102 with experiences that vary. They have had different types of work terms with varying levels of responsibly. In addition, some students may have extracurricular leadership experience, others may not. Because of this variety, ENGI 7102 was designed to offer support to students who may not have had the opportunity to formally learn about a particular professional skill while not requiring students who had already mastered the skill to attend a traditional class. For example, if a student required additional instruction and support for communication skills, this was available online. The student could complete this portion of the course and then be assessed on their learning. If a student had already acquired communication skills before coming into ENGI 7102, they were asked to demonstrate the skill by completing the required assignments.

ENGI 7102 is offered concurrently with the capstone design project courses in each department. Students are typically very engaged in their design projects and place a great deal of value on the course. For this reason, the design project was chosen as the case study that students would use to demonstrate their professional skills. The ways in which engineering educators integrate professional skills into their courses helps to determine students' attitudes about these skills, how they engage with the course and how important they consider those skills to be to engineering practice [5]. They were assessed on their teamwork, leadership, communication, professionalism, and ethics and equity in the context of 
their own design project. It was felt that by associating ENGI 7102 with a project that is typically valued by the students that sense of value would extend to the attributes being taught and assessed in ENGI 7102.

\subsection{Assessment}

Students were assessed using a combination of tools available in the Desire2Learning learning management system (LMS). The learning outcomes for the course were entered and tied to competencies that mirrored the CEAB graduate attributes (Table 1).

\section{Table 1}

\begin{tabular}{|c|c|c|}
\hline Learning Outcomes & $\begin{array}{l}\text { Graduate } \\
\text { Attribute }\end{array}$ & Assessment \\
\hline $\begin{array}{l}\text { Evaluate various critiques of the } \\
\text { relationship between technology } \\
\text { and society in order to make } \\
\text { more informed professional } \\
\text { decisions. }\end{array}$ & 8.3 & $\begin{array}{l}\text { Assignments, } \\
\text { LLL Plan, Quiz }\end{array}$ \\
\hline Develop a lifelong learning plan. & 12.3 & LLL Plan \\
\hline $\begin{array}{l}\text { Evaluate their own career path } \\
\text { and expectations in relation to the } \\
\text { standards of professional } \\
\text { engineering conduct }\end{array}$ & 8.3 & $\begin{array}{l}\text { Assignment, LLL } \\
\text { Plan }\end{array}$ \\
\hline $\begin{array}{l}\text { Communicate technical } \\
\text { information in a clear, effective, } \\
\text { and professional manner using } \\
\text { oral, written, and graphic delivery } \\
\text { methods. }\end{array}$ & 7.3 & $\begin{array}{l}\text { Assignment, } \\
\text { Term Paper, } \\
\text { Presentation }\end{array}$ \\
\hline $\begin{array}{l}\text { Demonstrate a conscientious } \\
\text { understanding of and } \\
\text { commitment to applying } \\
\text { sustainable design concepts in } \\
\text { engineering decisions. }\end{array}$ & 9.3 & $\begin{array}{l}\text { Term paper, } \\
\text { presentation }\end{array}$ \\
\hline $\begin{array}{l}\text { Apply problem-solving strategies } \\
\text { and techniques that take into } \\
\text { account the broader social, } \\
\text { ethical, and environmental } \\
\text { impacts of engineering solutions. }\end{array}$ & 9.3 & $\begin{array}{l}\text { Term paper, } \\
\text { presentation, quiz }\end{array}$ \\
\hline $\begin{array}{l}\text { Work effectively as a team } \\
\text { member and leader. }\end{array}$ & 6.3 & $\begin{array}{l}\text { Team contract, } \\
\text { group meetings, } \\
\text { individual } \\
\text { meetings, quiz } \\
\end{array}$ \\
\hline $\begin{array}{l}\text { Evaluate various critiques of the } \\
\text { relationship between technology } \\
\text { and society in order to make } \\
\text { more informed professional } \\
\text { decisions. }\end{array}$ & $8.3,10.3$ & $\begin{array}{l}\text { Assignments, } \\
\text { term paper, quiz }\end{array}$ \\
\hline \multicolumn{3}{|c|}{$\begin{array}{l}* \text { level } 1 \text { - introductory, level } 2 \text { - intermediate, level } 3 \text { - sophisticated } \\
* 1.2 \text { represents the first graduate attribute, engineering knowledge, at an } \\
\text { intermediate level }\end{array}$} \\
\hline
\end{tabular}

Rubrics were developed for each assignment and targets and thresholds were assigned to the rubrics. Each assignment had a dropbox folder with a rubric attached and learning outcomes linked. The instructor and a team of teaching assistants used the rubrics to assess the learning outcomes and determine which students were meeting the targets and thresholds. Statistics were gathered using the LMS.
Assignments, reflections, projects and online quizzes were used to assess student learning. The assignments consisted of targeted assessments of leadership, teamwork, ethics, and communication skills.

These assessments combined structured and unstructured group and individual activities. In teamwork, students were assessed on structured activities and well as their ability to work in a group setting. Both well-structured tasks and the co-creation occurring during the student's teamwork experience should be present for effective assessment of teamwork [13]. Students received online instruction in teamwork theory and techniques, and individual assignments and group work were used as a combined approach to teamwork assessment. To incorporate teamwork effectively, students should be educated in the importance of team dynamics including norms and expectations under which they may be expected to work, and there must be some way to reward individual work within the team [12].

Reflection is a key component in professionalism and lifelong learning. The reflective component of this course included building a Lifelong Learning Plan. Students were asked to reflect on their leadership, teamwork, ethics, communication and professional skills, establish goals for each skill, and create a plan to achieve those goals. The Lifelong Learning Plan was assessed using a rubric designed to assess reflective learning.

A significant portion of the assessment in ENGI 7102 was a term project that used the capstone design project as a case study. The term project included developing a team contract, progress meetings, presentations and a term paper. Teamwork skills were assessed using the team contract, the meetings and in an interview. In the interview, students were asked to reflect on their group's performance with respect to teamwork and discuss their own strengths and weaknesses in this area. Students were asked to identify what they brought to the team using concrete examples, and asked about the skills their team mates brought, again using concrete examples. Students were assessed on their ability to reflect on their performance, not on the performance itself.

Small group meetings were uses as formative and summative assessment, and to build a relationship between the students and the instructional team. Where classes are large and each assignment is evaluated by different marker, extra effort by the instructor may be required to establish a relationship of mutual respect so that students are more likely to be motivated and receptive to advice [1]. Twice during the semester, each group met with the instructor or a member of the instructional team for a coaching session on the term project. Students were responsible for developing the agenda, leading and actively participating in the meeting. Students were given formative assessment on their term 
paper and summative assessment on their professional skills.

In the first meeting, groups and their coach discussed the direction the students were taking with a term paper that would delve into the social, ethical and environmental impacts of their capstone design project. The coaches used Socratic questioning techniques to guide the students into considering the potential impacts in a sophisticated manner that acknowledged the complexities of the various issues [2]. In a follow up meeting, the coach checked in on the group's progress, and gave more guidance through questioning. Students were given formative assessment on their term paper and the meeting was also used a summative evaluation of their professional skills

\section{CONCLUSION}

To ensure graduating engineering students are successful in their careers, Memorial University's FEAS redeveloped the final stage of the Professional Skills Development learning stream. ENGI 7102 The Engineering Profession was redesigned to a blended model where theory is made available using online resources and large class, small group and individual activities are used to reinforce and assess this learning. This approach allows for differences in skill development and experiences of students. Resources are available for students who need more development and those with well-developed skills can directly complete assessments to demonstrate proficiency.

The course focuses on teamwork, leadership, communication, professionalism, ethics, the impact of engineering on society and the environment and lifelong learning. Learning outcomes are connected to graduate attributes to aid in streamlined reporting for accreditation. Extensive use of rubrics is needed to ensure consistency of assessment throughout the instructional team and these rubrics were designed to directly connect the learning outcomes to graduate attributes.

To increase connection and enthusiasm for the course, activities were closely connected to the capstone design project. Students used their project as a case study to demonstrate their professional skills and to integrate social, ethical and environmental impacts into the design process.

This blended approach allows more time for small group and individual meetings with instructors. These meetings include both formative and summative assessment of students' process skills and helps connect faculty and students in a way that is not possible in a traditional large class structure.

\section{References}

[1] G. M. Blair and C. M. Robinson, "Professional skills for first-year engineering students," Engineering Science and Education Journal, February, 1995.

[2] Timothy Carey, "What is Socratic questioning," Psycotherapy: Theory, Research, Practice, Training, vol. 41, no. 3, pp. 217-226, 2004.

[3] Engineers Canada, Canadian Engineering Accreditation Board, "2010 Accreditation Criteria and Procedures", www.engineerscanada.ca, 2010.

[4] Margaret Faulkner, Syed Mahfuzul Aziz, Vicki Waye \& Elizabeth Smith, "Exploring ways that ePortfolios can support the progressive development of graduate qualities and professional competencies," Higher Education Research \& Development, vol. 32, no. 6, pp. 871-887, 2015.

[5] Debra Gibuena and Milo Koretsky, "Learning Professional Skills,” ASEE Prism, vol. 24, no. 6, pp. 39, 2015.

[6] Shihong Huang, Dragutin Petkovic, Kazunori Okada, Marc Sosnick, Shenhaochen Zhu and Rainer Todtenhoefer, "Toward objective and quantitative assessment and prediction of teamwork effectiveness in software engineering courses," ACM SIGSOFT Software Engineering Notes, vol. 38, no. 1, pp. 7-9, 1995.

[7] P. King, \& K. Kitchener, "The reflectivement model: Twenty years of research on epistemic cognition." In B. Hofer \& P. Pintrich (Eds.), Personal Epistemology: The Psychology of Beliefs about Knowledge and Knowing, pp. 37-62. New Jersey, NJ: Lawrence Erlbaum Associates, 2004.

[8] "Memorial University of Newfoundland Calendar" [online] 2015, http://www.mun.ca/regoff/calendar/ (accessed: 15, April 2015).

[9] A. Mohan, D. Merle, C. Jackson, C. Lannin and S.S. Nair, "Professional skills in the Engineering Curriculum," Education, IEEE Transactions on, vol. 53, no. 4, pp. 562572,2010 .

[10] Mary Peat, Charlotte Taylor and Sue Franklin, "Reengineering of undergraduate science curricula to emphasise development of lifelong learning skills," Innovations in Education and Teaching International, vol. 42, no. 2, pp. 135-146, 2005.

[11] C. Tenopir and D. W. King, Communication Patterns of Engineers. New York: IEEE/Wiley InterScience, 2004.

[12] Arabella Volkov and Michael Volkov, "Teamwork and assessment: A critique," e-Journal of Business Education \& Scholarship of Teaching, vol. 1, no. 1, pp. 59-64, 2007.

[13] Arabella Volkoy and Michael Volkoy, "Teamwork benefits in tertiary education," Education + Training, vol. 57, no. 4, pp. 262-278, 2015.
CEEA15; Paper 072

McMaster University; May 31 - June 3, 2015 